\title{
Biomass Combustion Fly Ash-Derived Nanoporous Zeolites for Post- Combustion Carbon Capture
}

\author{
Ben Petrovic, Mikhail Gorbounov, Abhishek Lahiri and Salman Masoudi Soltani \\ Department of Chemical Engineering, Brunel University London, Uxbridge UB8 3PH, United \\ Kingdom
}

\begin{abstract}
Achieving negative $\mathrm{CO}_{2}$ emissions via the combustion of sustainable biomass - known as bioenergy with carbon capture and storage - is inherently linked to the coproduction of a significant amount of potentially hazardous waste combustion fly ash. Valorisation of this solid waste stream presents obvious economic, social, and environmental incentives within the context of waste utilisation and environmental protection. However, the origin of the biomass (the regional plantation) used during the combustion, dictates the physicochemical properties of this solid residue, making it suitable for specific applications while rendering it less favourable for others.

In this study, a nanoporous zeolite as a $\mathrm{CO}_{2}$ adsorbent has been synthesised from industrial-grade biomass combustion fly ash generated in one of the largest biomass combustion power plants in the UK. The method of nanoporous zeolite synthesis follows a fusion-assisted hydrothermal procedure and the produced nanoporous zeolite has been characterised by $\mathrm{X}$-ray diffraction. The $\mathrm{CO}_{2}$ adsorption investigations were conducted via thermogravimetric analysis to estimate the uptake capacity of the prepared adsorbents. TGA studies suggest that the nanoporous adsorbent, run under $100 \mathrm{~mol} \%$ $\mathrm{CO}_{2}$ at atmospheric pressure, has an equilibrium capacity of over $0.8 \mathrm{mmol} \mathrm{CO}_{2} / \mathrm{g}$ at $50{ }^{\circ} \mathrm{C}$. The characterisation results are in good agreement with our $\mathrm{CO}_{2}$ adsorption data, demonstrating the nanoporous structure of our synthesised waste-derived zeolites.
\end{abstract}

\section{INTRODUCTION}

The climate crisis we are currently enduring is attributed to the emission of certain anthropogenic greenhouse gases which include carbon dioxide, methane and nitrous oxide. $\mathrm{CO}_{2}$ however, has been, and still is considered the most significant of these gases especially when the extent of its emission is considered [1]. In 2019, the UK become the first major global economy to legislate for net-zero greenhouse gas (GHG) compared to 1990 levels by the year 2050 [2]. This climate emergency declaration was a result of sustained public pressure during the early summer. Since then, over 100 countries have followed suit and pledged for net-zero either on or before 2050 [3]. In the UK context, $\mathrm{CO}_{2}$ emissions present over $80 \%$ of the GHG emissions during the years between 1990 and 2018 [4]. In order to successfully limit global temperature rise to less than $2{ }^{\circ} \mathrm{C}$ [5], technologies such as Carbon Capture and Storage (CCS) are indispensable. Post-combustion carbon capture (PCCC) refers to processes which involve the removal of
$\mathrm{CO}_{2}$ from various types of flue gases e.g. those generated at power plants, cement and steel manufacture. Whilst it may be possible to directly remove $\mathrm{CO}_{2}$ from the atmosphere, the principal interests lie with the separation of $\mathrm{CO}_{2}$ from large-point sources such as thermal power plants where the concentration of $\mathrm{CO}_{2}$ is more favourable and the potential for emission reductions greatest [6].

In the Intergovernmental Panel on Climate Change's (IPCC) Fifth Assessment Report, 116 scenarios associated with an atmospheric concentration of $\mathrm{CO}_{2}$ between 430 and $480 \mathrm{ppm}$ in the year 2100 were identified, of which, 100 were dependent on the deployment of Bioenergy with Carbon Capture and Storage (BECCS) [7]. Although BECCS encompasses a group of technologies that span over a number of sectors, efforts have been focused on either BECCS via liquid biofuel production or BECCS via biomass conversion to heat and power. With the former predicted to account for over $60 \%$ of the primary energy available for BECCS processes [8]. In the latter process, BECCS combines the combustion of sustainable biomass (a net-zero emission process) with PCCC. The conversion of biomass to heat through combustion, which assuming a mean ash yield of $6.8 \%$ [9] results in a significant quantity of co-generated waste fly ash. For example, during 2019 , Drax power station burnt over $7 \mathrm{Mt}$ of biomass enabling them to produce $12 \%$ of the UK's renewable energy [10], this $13.4 \mathrm{TWh}$ of energy accounts for around $40 \%$ of the UK's total bioenergy production [11]. In the UK around 30 $\%$ of fly ash is directly landfilled [12] and given the concerns around environment contamination, dangerous alkalinity and leaching, valorisation of this waste is of paramount importance not just in the context of the environment, but also socially and economically [13]. Fly ash contains an abundance of raw aluminosilicates that can be converted into zeolites by well-documented procedures [14]. Zeolites are established solid sorbents for the selective adsorption of $\mathrm{CO}_{2}$ in the post-combustion context [15], exploitation of this resource could be a simple yet efficiently viable route towards the accelerated deployment of BECCS in the UK and around the world.

\section{MATERIALS AND Methodology}

The biomass combustion fly ash (BFA) precursor employed in this work was collected from a biomass 
combustion facility in the UK. The BFA has been extensively characterised by Scanning Electron Microscopy (SEM, LEO 1455VP), Energy Dispersive XRay Spectroscopy (EDS, Edax International Ltd.), Fourier Transform Infrared spectrometry (FTIR, Perkin Elmer Spectrum One), X-Ray Diffraction (XRD, Bruker D8) and Particle Size Analysis (PSA, Beckman-Coulter LS230). The nanoporous zeolites were synthesized using a fusionassisted, hydrothermal procedure [16], [17] to increase the solubility of the complex $\mathrm{Si}$ and Al species [14] in the BFA reducing the synthesis time whilst simultaneously increasing crystallinity and yield [14], [18] when compared to the conventional hydrothermal method [19].

The BFA (10g) was mixed with $\mathrm{NaOH}$ Pellets (16g, Sigma Aldrich) and ground in a pestle and mortar. This mixture was then fused in a muffle furnace at $550{ }^{\circ} \mathrm{C}$ for 1 hour after which the fusion product was cooled and ground in a pestle and mortar. Deionised water $(100 \mathrm{ml})$ was then added to a PTFE liner followed by $13 \mathrm{~g}$ of the ground fusion product. This solution was then magnetically stirred at 300 rpm for 16 hours. Subsequently, the PTFE liner was inserted into a stainless-steel pressure digestion vessel (Berghof DAB-3) and then heated at $90{ }^{\circ} \mathrm{C}$ for 4 hours. The product was then separated via vacuum filtration, washed with deionized water until $\mathrm{pH} 7$ and dried at $110{ }^{\circ} \mathrm{C}$ overnight. The produced zeolite has been characterized using XRD and evaluated for $\mathrm{CO}_{2}$ adsorption performance via Thermal Gravimetric Analysis (TGA, TA Instruments Ltd. SDT-Q600). The adsorption performance the sample was measured at $50{ }^{\circ} \mathrm{C}$, under a gas flow rate of $50 \mathrm{mlmin}^{-}$ ${ }^{1} \mathrm{CO}_{2}(99.9 \%)$ at atmospheric pressure for 2 hours.

\section{RESULTS AND DISCUSSION}

\section{A. Biomass Fly Ash Characterization}

Given the nature of BFA i.e. non-conductive, the sample was gold coated via the gold-sputtering technique and then used to assess its surface morphology. The SEM image can be seen in Fig. 1. The ash is comprised of a combination of spherical particles with wide size variation, agglomerations of these particles and a selection of porous elements. The spherical particles or cenospheres are typical of fly ash and can be attributed to their amorphous coating formed as a result of relatively abrupt cooling post-combustion [20]. It has also been observed that the cenospheres present hollow

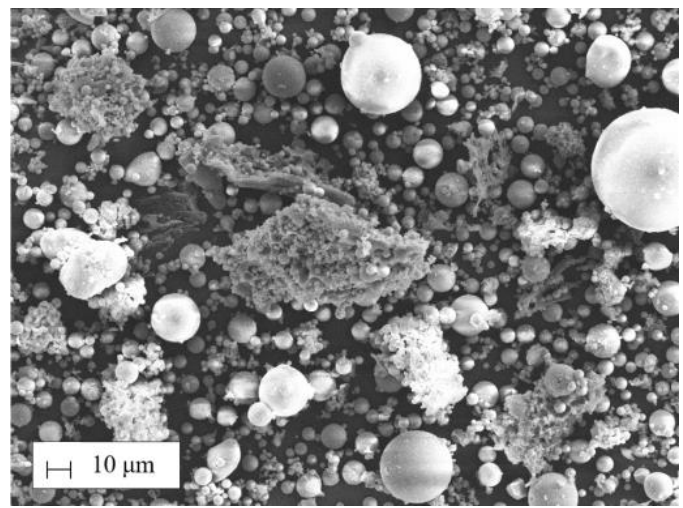

microspheres of aluminosilicate glass shells that possess inclusions of various crystalline phases such as quartz or mullite [16], [21].

The EDS analysis of this sample elucidated to the presence of a significant amount of oxygen, silicon, aluminium and calcium as well as potassium, iron, magnesium and sodium. Trace amounts of phosphorous and sulphur were also identified. The high prevalence of oxygen indicates that there exists a large quantity of oxides such as $\mathrm{Al}_{2} \mathrm{O}_{3}$ and $\mathrm{SiO}_{2}$. Several areas were analysed, and an average weight percent of the elements present are exhibited in TABLE 1 .

TABLE 1: The EDS elemental analysis of the BFA.

\begin{tabular}{|c|c|}
\hline Element & Weight (\%) \\
\hline $\mathrm{Na}$ & 1.66 \\
\hline $\mathrm{Mg}$ & 2.01 \\
\hline $\mathrm{Al}$ & 9.15 \\
\hline $\mathrm{Si}$ & 14.28 \\
\hline $\mathrm{P}$ & 0.13 \\
\hline $\mathrm{S}$ & 0.70 \\
\hline $\mathrm{K}$ & 7.91 \\
\hline $\mathrm{Ca}$ & 8.54 \\
\hline $\mathrm{Fe}$ & 3.78 \\
\hline $\mathrm{O}$ & 51.84 \\
\hline
\end{tabular}

By mixing $\mathrm{BFA}$ with $\mathrm{KBr}$ powder and pressing into a disc, the infrared spectra collected in the region of $4000-$ $450 \mathrm{~cm}^{-1}$ elucidated the presence of several bonds within the BFA. Most notably, the peaks at 1628.3 and $1384.85 \mathrm{~cm}^{-1}$ which were ascribed to the stretching and bending vibrations of the O-H bond [22], [23] present as either physisorbed moisture or hydroxides within the ash. The carbonyl group was identified at 1410.45 and $875.84 \mathrm{~cm}^{-1}$ and denoted as the asymmetric tensile stretching and bending vibrations of the double bond, respectively [24], [25]. Si-O bonds have also been identified at 1020.07 and $689.07 \mathrm{~cm}^{-1}$ typical of aluminosilicate structures [23], [26]. The substitution of Si atoms by $\mathrm{Al}$ in the tetrahedral position of the formation leads to a lower binding energy between the $\mathrm{O}$ and $\mathrm{Si}$ atoms which decreases the asymmetric stretching vibration band from c. $1100 \mathrm{~cm}^{-1}$ for $\mathrm{Si}-\mathrm{O}-\mathrm{Si}$ compounds to a lower wave number for $\mathrm{Si}-\mathrm{O}-(\mathrm{Al})$ bond types.

TABLE 2: Phases present in the XRD pattern and their associated powder diffraction files (PDF).

\begin{tabular}{|c|c|}
\hline Phase & PDF \\
\hline Lime & $00-037-1497$ \\
\hline Calcite & $00-066-0867$ \\
\hline Hematite & $01-073-8431$ \\
& $00-024-0072$ \\
\hline Portlandite & $01-070-5492$ \\
\hline Boehmite & $00-021-1307$ \\
\hline Potassium Oxide & $01-077-2176$ \\
\hline Kalicinite & $01-070-0995$ \\
\hline Periclase & $01-071-1176$ \\
\hline Mullite & $01-074-4146$ \\
\hline Quartz & $01-074-1811$ \\
\hline
\end{tabular}

Fig. 1: SEM image of BFA, $15 \mathrm{kV}, 300 \mathrm{pA}$ and $1 \mathrm{kx}$ mag. 
The XRD pattern corroborated the EDS analysis although the presence of sodium and other trace elements was not observed. As expected, the fly ash is a mixture of aluminosilicates with an abundance of inorganic mineral phases such as metal oxides and carbonates.

TABLE 2 exhibits the phases that were identified during the analysis and the powder diffraction file (PDF) associated with each. Crystalline quartz, mullite, hematite, portlandite and calcite were registered which are all typical of fly ashes.

Particle size analysis of the BFA indicated 4 distinct peaks as can be seen in Fig. 2 which can be interpreted in two ways. The first being a distribution that possesses 4 distinct maximums at 12,30, 70 and 161ums; the second being that the BFA is comprised of 2 independent bi-modal distributions of non-spherical particles, the aspect ratio of which can be inferred from the two peaks. However, since the BFA is seen to be predominately spherical, it can be assumed that the PSA identified a distribution with 4 distinct maximums.

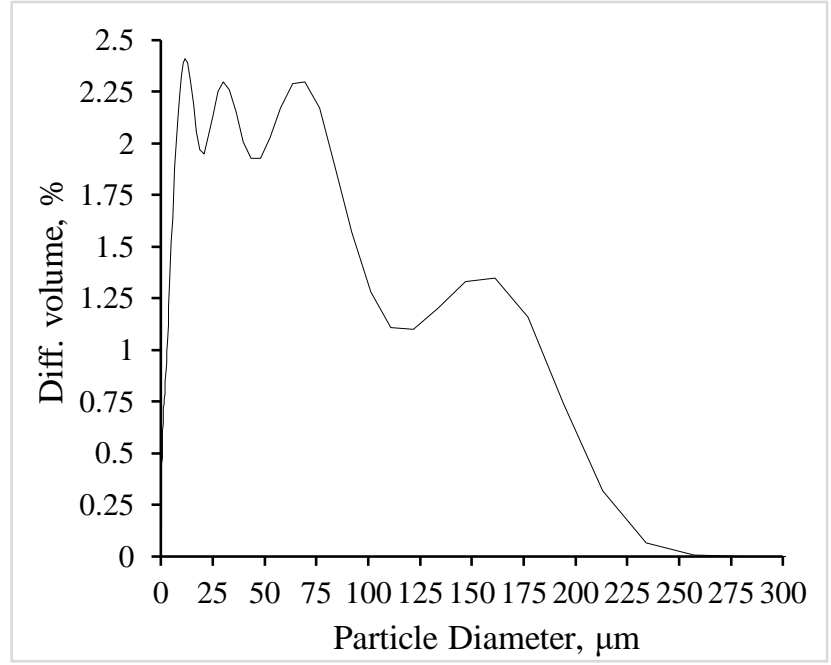

Fig. 2:Particle size distribution plot for raw-BFA.

\section{B. Biomass Fly Ash Derived-Zeolite Characterisation}

The diffractograms of the studied zeolite produced from BFA did not indicate pure crystalline phases. It is clear though, that no reflexes of the phases present in the raw BFA were found. This suggests that fusing the BFA with $\mathrm{NaOH}$ at $550{ }^{\circ} \mathrm{C}$ for 1 hour is suitable for the conversion of BFA into sodium silicate and sodium aluminate species which are favourable for the hydrothermal reaction [14]. However, the lack of distinct peaks representative of crystalline zeolites indicates that the conditions during the hydrothermal treatment may not be suitable for producing highly crystalline phases or that the scan duration in the $\mathrm{XRD}$ analyses is not sufficient.

\section{C. $\mathrm{CO}_{2}$ Adsorption Performance}

The performance of the BFA-derived zeolite in the adsorption of $\mathrm{CO}_{2}$ was evaluated using TGA apparatus. The adsorption kinetics curve can be seen in Error! Reference source not found. and demonstrates that the synthesised zeolite presents a $\mathrm{CO}_{2}$ adsorption capacity of 0.825 $\mathrm{mmol}_{\mathrm{CO} 2} / \mathrm{g}$ at $50{ }^{\circ} \mathrm{C}$. Additionally, it has been found that when regenerating the BFA-derived adsorbent, there is the potential for complete regeneration at $150{ }^{\circ} \mathrm{C}$ under nitrogen flow.

\section{CONCLUSION}

This study suggests that the fusion-assisted hydrothermal method results in moderately zeolitic adsorbents that can effectively and reversibly adsorb $\mathrm{CO}_{2}$. However, due to the inability to identify highly crystalline or pure zeolite phases within the product, manipulation of the experimental conditions during the hydrothermal treatment should result in more effective and better performing zeolitic adsorbents. The sorbent prepared in this work, showed a $\mathrm{CO}_{2}$ update capacity of $0.825 \mathrm{mmol}_{\mathrm{CO} 2} / \mathrm{g}$ at $50{ }^{\circ} \mathrm{C}$ under a pure $\mathrm{CO}_{2}$ flow rate. Even with the lack of pure, crystalline zeolitic phases, the capacity demonstrated by the adsorbent is sufficient to suggest improvements can be made that would realise a competitive adsorbent for the removal or $\mathrm{CO}_{2}$ from large-point sources. As a result, further investigations are deemed necessary to improve the adsorption capacity of this cost-effective waste-derived adsorbent, which may find great potentials in PCCC.

\section{ACKNOWLEDGMENT}

This work has been funded by the UK Carbon Capture and Storage Research Centre (EP/P026214/1) through the flexible funded research programme "Biomass Combustion Ash in Carbon Capture". The UKCCSRC is supported by the Engineering and Physical Sciences Research Council (EPSRC), UK, as part of the UKRI Energy Programme. The authors are grateful to the Research Centre for providing this funding. The authors would also like to acknowledge Brunel Research Initiative and Enterprise Fund (BRIEF) to support this work.

\section{REFERENCES}

[1] A. Rafiee, K. Rajab Khalilpour, D. Milani, and M. Panahi, "Trends in CO2 conversion and utilization: A review from process systems perspective," J. Environ. Chem. Eng., vol. 6, no. 5, pp. 5771-5794, 2018, doi: 10.1016/j.jece.2018.08.065.

[2] Committe on Climate Change and C. on C. Change, "Net Zero: The UK's contribution to stopping global warming," 2019.

[3] H. L. van Soest, M. G. J. den Elzen, and D. P. van Vuuren, "Net-zero emission targets for major emitting countries consistent with the Paris Agreement," Nat. Commun., vol. 12, no. 1, Dec. 2021, doi: 10.1038/s41467-021-22294-x.

[4] P. Brown et al., "UK Greenhouse Gas Inventory, 1990 to 2018. Annual Report for Submission under the Framework Convention on Climate Change," London, 2020.

[5] E. Commission and European Commission, "Paris Agreement | Climate Action," European Commission Climate Action, 2015. https://ec.europa.eu/clima/policies/international/negotiations/pa ris_en.

[6] E. I. Koytsoumpa, C. Bergins, and E. Kakaras, "The CO2 economy: Review of CO2 capture and reuse technologies," $J$. Supercrit. Fluids, vol. 132, no. July 2017, pp. 3-16, 2018, doi: 10.1016/j.supflu.2017.07.029. 
[7] R. K. Pachauri et al., Climate change 2014: synthesis report. Contribution of Working Groups I, II and III to the fifth assessment report of the Intergovernmental Panel on Climate Change. Geneva, Switzerland: Ipcc, 2014.

[8] M. Muratori, H. Kheshgi, B. Mignone, L. Clarke, H. McJeon, and J. Edmonds, "Carbon capture and storage across fuels and sectors in energy system transformation pathways," Int. J. Greenh. Gas Control, 2017, doi: 10.1016/j.ijggc.2016.11.026.

[9] S. V. Vassilev, D. Baxter, L. K. Andersen, and C. G. Vassileva, "An overview of the chemical composition of biomass," Fuel. 2010, doi: 10.1016/j.fuel.2009.10.022.

[10] Drax group, "Drax Annual Reports and Accounts," 2019.

[11] UK Committee on Climate Change, "Biomass in a low-carbon economy," 2018. https://www.theccc.org.uk/wpcontent/uploads/2018/11/Biomass-in-a-low-carbon-economyCCC-2018.pdf.

[12] U. Q. A. A. (UKQAA), “Ash Utilisation Data,” 2018. http://www.ukqaa.org.uk/.

[13] J. Li, X. Zhuang, X. Querol, O. Font, and N. Moreno, “A review on the applications of coal combustion products in China," Int. Geol. Rev., vol. 60, no. 5-6, pp. 671-716, 2018, doi: 10.1080/00206814.2017.1309997.

[14] C. Belviso, "State-of-the-art applications of fly ash from coal and biomass: A focus on zeolite synthesis processes and issues," Prog. Energy Combust. Sci., vol. 65, pp. 109-135, 2018, doi: 10.1016/j.pecs.2017.10.004.

[15] B. Petrovic, M. Gorbounov, and S. Masoudi Soltani, "Influence of surface modification on selective $\mathrm{CO} 2$ adsorption: A technical review on mechanisms and methods," Microporous Mesoporous Mater., no. October, p. 110751, Nov. 2020, doi: 10.1016/j.micromeso.2020.110751

[16] S. Boycheva, D. Zgureva, H. Lazarova, and M. Popova, "Comparative studies of carbon capture onto coal fly ash zeolites Na-X and Na-Ca-X," Chemosphere, vol. 271, p. 129505, 2021, doi: 10.1016/j.chemosphere.2020.129505.

[17] D. Zgureva and S. Boycheva, "Experimental and model investigations of $\mathrm{CO} 2$ adsorption onto fly ash zeolite surface in dynamic conditions," Sustain. Chem. Pharm., vol. 15, no. January, p. 100222, 2020, doi: 10.1016/j.scp.2020.100222.

[18] A. Dindi, D. V. Quang, L. F. Vega, E. Nashef, and M. R. M. Abu-Zahra, "Applications of fly ash for $\mathrm{CO} 2$ capture, utilization, and storage," J. CO2 Util., vol. 29, no. November 2018, pp. 82-102, 2019, doi: 10.1016/j.jcou.2018.11.011

[19] S. S. Bukhari, J. Behin, H. Kazemian, and S. Rohani, “A comparative study using direct hydrothermal and indirect fusion methods to produce zeolites from coal fly ash utilizing single-mode microwave energy," J. Mater. Sci., vol. 49, no. 24, pp. 8261-8271, 2014, doi: 10.1007/s10853-014-8535-2.

[20] D. Mainganye, T. V. Ojumu, and L. Petrik, "Synthesis of zeolites Na-P1 from South African coal fly ash: Effect of impeller design and agitation," Materials (Basel)., 2013, doi: 10.3390/ma6052074

[21] S. V. Vassilev, R. Menendez, M. Diaz-Somoano, and M. R. Martinez-Tarazona, "Phase-mineral and chemical composition of coal fly ashes as a basis for their multicomponent utilization. 2. Characterization of ceramic cenosphere and salt concentrates," Fuel, vol. 83, no. 4-5, pp. 585-603, Mar. 2004, doi: 10.1016/j.fuel.2003.10.003.

[22] M. Gómez et al., "Development of mesoporous materials from biomass ash with future applications as adsorbent materials," Microporous Mesoporous Mater., vol. 299, no. January, p. 110085, Jun. 2020, doi: 10.1016/j.micromeso.2020.110085.

[23] W. Mozgawa, M. Król, J. Dyczek, and J. Deja, "Investigation of the coal fly ashes using IR spectroscopy," Spectrochim. Acta - Part A Mol. Biomol. Spectrosc., vol. 132, pp. 889-894, Nov. 2014, doi: 10.1016/j.saa.2014.05.052.

[24] M. Assad Munawar et al., "Biomass ash characterization, fusion analysis and its application in catalytic decomposition of methane," Fuel, vol. 285, no. May 2020, p. 119107, Feb. 2021, doi: 10.1016/j.fuel.2020.119107.

[25] P. Chindaprasirt and U. Rattanasak, "Characterization of porous alkali-activated fly ash composite as a solid absorbent," Int. J. Greenh. Gas Control, vol. 85, no. March, pp. 30-35, 2019, doi: 10.1016/j.ijggc.2019.03.011.
[26] Y. Chen, C. Zou, M. Mastalerz, S. Hu, C. Gasaway, and X. Tao, "Applications of Micro-Fourier Transform Infrared Spectroscopy (FTIR) in the Geological Sciences-A Review," 2015, doi: 10.3390/ijms161226227. 